\title{
The Problem of "Sense - Meaning - Concept" in the Context of Modern Intercultural Communication as a Reflection of the Processes of Globalization and Migration
}

\author{
Yulia N. Ebzeeva ${ }^{1}$, Irina S. Karabulatova ${ }^{1, *}$, Elvira F. Mukhamadieva ${ }^{2}$, Karpis S. \\ Anumyan $^{1}$
}

\author{
${ }^{I}$ Department of Foreign Languages of the Philological Faculty, Peoples' Friendship University of Russia (RUDN- \\ university), Moscow, Russia \\ ${ }^{2}$ Ufa State Petroleum Technological State University, Ufa, Russia \\ * Corresponding author. Email: radogost2000@mail.ru
}

\begin{abstract} Psycholinguistics, Philosophy, Psychology.

\section{INTRODUCTION}

The linguistic and cultural effect of globalization and migration processes has not yet been fully evaluated, but our materials demonstrate the correlation between population migration, the use of high technologies and the change in the meanings of words used under the influence of intensive intercultural communication. First, it is the intensification of migration from Arabic - speaking countries to Europe and as a consequence-the spread of the Arabic language in European countries [1].

Modern research in the field of interpersonal and intercultural communication, psychology, social philosophy considers understanding as the key to successful communication. The lack of mutual understanding in the process of communication leads to the complication or destruction of relationships between people, to conflicts, and in the case of intercultural communication - to the rejection of another's culture, ethnophobia and cultural shock [2]. The relevance of the study of the problem of understanding as a phenomenon of intercultural communication, due, on the one hand, the development of humanitarian knowledge, on the other-the changes that have
\end{abstract}

The purpose of this study is to carry out linguistic and cultural analysis of understanding as a process and result of intercultural communication in the unity of its phenomenological and procedural components. The object of the research is communicative interaction in the modern information society in the context of interaction and understanding. It is suggested that understanding is not just a comprehension of meaning, but a dynamic system with an operational structure. Attempts are made to comprehend the mechanism of understanding, to highlight its levels, to determine the ways of structuring the understood object. Applications of this study: Theory of Language, intercultural communication, Social Economics,

Keywords: globalization, migration, communicative behavior, intercultural communication

occurred recently in the study of the nature of cognitive activity. Great progress has been made in understanding as a possibility of knowing someone else's individuality.

The problem of understanding is not new to modern science, but its solution is carried out in different ways in different branches of knowledge. The diversity of approaches is explained both by the known isolation of the various Sciences from each other, and, of course, by the complexity of the object itself. Differences of interpretation relate to almost everything except the recognition of the importance of the problem and the need to find a solution. Apparently, such a solution should be sought at the intersection of disciplines, because any branch of science is objectively limited, and understanding is a problem of a clearly interdisciplinary order.

The end of the 20th century put a person at risk of a cultural shock, called A. Toffler, furthered [3], which was caused by abrupt changes in his system of society and culture, which is expressed in: - acceleration of life rates; - changing environment (noosphere) and the lack of experience in it to live; - individualization of human needs, a variety of forms of the human environment.

Linguistic studies of the texts of mass communication in the context of the social changes that have taken place in Russia in recent decades are most closely related to such things as 
comparing texts of the Soviet and post-Soviet epoch, critical analysis of texts from the point of view of their compliance with standards, research of communicative strategies and tactics, and description new phenomena in the language system at its various levels. The relevance of the study of the problem of understanding as a phenomenon of intercultural communication, due, on the one hand, the development of humanitarian knowledge, on the other-the changes that have occurred recently in the study of the nature of cognitive activity.

Great progress has been made in understanding as a possibility of knowing someone else's individuality. It is suggested that understanding is not just a comprehension of meaning, but a dynamic system with an operational structure. Attempts are made to comprehend the mechanism of understanding, to highlight its levels, to determine the ways of structuring the understood object.

The relevance of the study is due to the general trends in the development of modern scientific and humanitarian thinking - a pronounced anthropocentrism, a view of the text as the highest communicative unit and linguocultural space, the realization that the solution of problems facing a particular humanitarian discipline is only possible on the path of integrating scientific paradigms from the standpoint of metatheoretical knowledge (V. S. Bibler, M. Makarov, M. V. Popovich, M. Foucault), with an orientation towards building an integral theory of the language (N. F. Alefirenko, N.S. Bolotnova, V.Z. Demyankov, V.V. Karasik, O.G. Revzina and others). The qualitative expansion of the sphere of objects of humanitarian knowledge makes more and more popular both the concepts of supertext and hypertext (in its different understandings), and the linguo-conceptual reality that stands behind them. In General, the development of the problem of understanding was carried out by the following areas of humanitarian knowledge. However, in recent years, this problem from a purely philosophical problem has become again relevant and in demand, in connection with machine learning and the actualization of the understanding of NLP by artificial intelligence [4].

Intensification of intercultural contacts by means of mass communication influences character of various sources of spiritual culture, including - speech, at the expense of opportunities of principal-substantial-formal-correction of information streams circulating in society. With the spread of new technologies of mass communication, the sociocultural and semantic-stylistic attitudes that are formed within the framework of written and oral speech culture become different.

Hermeneutics is an exegetical direction, represented mainly by medieval philosophers and theologians: Anselm of Canterbury, Thomas Aquinas, John Duns Scot, etc. the Main problem that was considered by medieval thinkers is the problem of unambiguity of translation of sacred texts and their interpretation (exegesis).

The development of the classification basis for the manifestation of the human factor in the language becomes possible as a result of the hierarchical ordering of the coordinates of the functional representation of the subject of cognition, which allows to show what particular human function a certain type of speech-thinking activity relies on. It is this line of analysis that seems necessary at the present stage of development of linguistic science.

The expansion of semiotics, which reveals "its objects everywhere - in language, mathematics, fiction ..., in architecture, in the processes of the subconscious ..." is due to the need to analyze "information systems" that form the limitless continuum of signs and form "the language of the world" and "the language of man" [5].

Anselm of Canterbury first turned to the technique of integration in connection with the problem of the existence of God. Further attention is paid to the phenomenon of understanding in connection with the problems of intentional comprehension of meaning (P. Abelard), and, later, the theory of sign ("formal indication" by John Duns Scotus, nominalist concept of William Occam). Through the hermeneutic school of the German Enlightenment (G. Ernesti, I. Semler) the problems of this direction are inherited by the German classical Philology.

Phenomenological direction was founded by the Czech philosopher and mathematician B. Bolzano, who for the first time drew a clear boundary between the formal meaning of a logical statement and its meaning (the sphere of "statements" and the sphere of "truths"). His follower, the Austrian psychologist and philosopher F. Brentano, introduces the concept of "intentionality" statements, considering it as a necessary condition for the comprehension of meaning. A serious impetus to the further study of the phenomenon of understanding was the fundamental discovery of G. Frege, who showed in 1892 that the ideal in the text consists of meanings (formants of content) and meanings - two components that are fundamentally irreducible to each other. The German philosopher of science E. Husserl, whose name is usually associated with the birth of phenomenology as a philosophical discipline, also adhered to this distinction, considering it through the dichotomy of "indication / expression".

Developing the ideas of G. Frege, the famous logician and methodologist G. P. Shchedrovitsky developed a number of hermeneutic techniques of understanding, called reflective. They allowed researchers to go beyond the decoding technique leading to the semantics of only predicative relationships within propositional structures.

As part of the phenomenological direction, it is also appropriate to mention the hermeneutic phenomenology of M. Heidegger and G. G. Gadamer, in a number of their works considering the basic characteristics of human everyday existence as a "matrix", a carrier of elementary meanings, through which one can also comprehend the meaning of more complex "formations" — both linguistic (literature) and cultural-historical (works of art, historical events, etc.).

The projections of the text, formed in the mind of the addresser and the addressee, are mediated by the communicational conceptospheres and marked with an individual interpreter, that is, reference attitudes in the procedure of perception and reflection of reality, as well as decoding of semiotic codes.

The philological and linguistic direction was presented in the early 19th century in Germany by the names of $\mathrm{F}$. Schleiermacher and V. von Humboldt. These authors considered the problem of understanding in intercultural communication in linguistic and socio-philosophical aspects. V. von Humboldt and F. Schleiermacher, developing the mechanism of unconscious language proficiency, emphasized the important role of language in thinking and cognition, as well as in the creation of a specific culture of the people. Later, studies were conducted on the category of mentality and the existential component of understanding in the communication of representatives of different cultures.

The ability of a linguistic sign to act as a symbol of a designated object is marked by E. Benveniste as a natural 
result of mental operations that predetermine one or another cognitive content: "The ability to symbolize is the basis of mental functions. Thinking is nothing but the ability to create representations of things and operate with these representations. It is by nature symbolic. The symbolic transformation of elements of reality or experience into concepts is a process through which the logizing ability of the mind is carried out. Thought not only reflects the world, it categorizes reality, and in this organizing function it so closely connects with the language that one even wants to identify thought and language from this point of view (Benvenist, E. 1998). Proceeding from the statement about the "humanized nature of language", E. Benveniste claims that linguistic semiosis is "representative in its essence representative ability, which lies at the basis of the formation of concepts, appears only in man" [6]. The ability to symbolize is understood by a linguist as gnoseologically conditioned, since it allows "to represent (represent) objective reality with the help of a"sign"and to understand"asign"as a representative of objective reality ..." [6].

The basis of the symbolization procedure is represented by mental processes of conceptual categorization, which give "the possibility of the formation of concepts as something different from a specific object" and determine the content side of the sign.

She, in turn, "is both the principle of abstraction and the basis of creative imagination" [6]. Formulating the thesis about the "property of double meaning" of linguistic units, Benveniste notes the correlation of form and meaning, thereby limiting the attempts of anti-mentalists to exclude meaning from the scope of linguistic research: "... all of them must necessarily proceed from the fact that their object, language, is endowed with the meaning that it is precisely because of this that it is the structure, and that this is the basic condition for the functioning of the language among other sign systems" [6].

Significance is the side of the linguistic sign in which the representations of a person about the diversity of the surrounding world (material and spiritual) are represented, determined by the conventions of the national and individual world perception and are the natural result of his nominative activity. and an integral effective component of communication.

Currently, this approach is to recognize the role of understanding as the main factor determining the success of communication. E. M. Vereshchagin and V. G. Kostomarov, as well as S. G. Ter-Minasova, consider "mutual cultural code", known to all communicants, a basic condition for mutual understanding in intercultural communication. R. Henvey introduces the concept of "cross-cultural literacy" as a system of knowledge that allows free communication with representatives of other cultures. The content space of the decoded text is formed as a hierarchy of cognitive levels, represented by levels of explicit and implicit information (verbalized in text characters), information formed by the propositional, frame, conceptual network and formed into the labial system actualized in the consciousness of the recipient of knowledge.

Linguoculturological direction is associated with the works of the famous American linguist B. Whorf, who, together With E. Sepir formulated the hypothesis of linguistic relativity. Linguistic relativity as a scientific concept originates from the works of the founder of ethnolinguistics, American anthropologist F. Boas. The most important stage in the study of language as a means of systematization of cultural experience is associated with the works of E. Sepir. Understanding linguistic relativity as the inability to establish component-by-component correspondences between systems of different languages, sepir coined the term "incommensurability" of languages. Language systems of individual languages not only fix the content of cultural experience in different ways, but also provide their carriers with different ways of understanding reality and ways of its perception. The most radical views on the "picture of the world of the speaker" as a result of the action of linguistic mechanisms of conceptualization were expressed by B. Whorf. The instrument of conceptualization, according to Whorf, is not only the formal units allocated in the text, but also the selectivity of language rules, and compatibility in each language.

M. M. Bakhtin and L. A. Mikeshina devoted their works to the study of the phenomenon of understanding. M. M. Bakhtin put forward the linguo-cultural concept of the dialogue of cultures, considering dialogue as the basis of dialectics, and understanding as the space of meanings and knowledge arising in the development of culture (1997).

Currently, the idea of the existence of some meta-cultural meaning, some common conceptual background, differently represented in different cultures, but guaranteeing the General significance of the content that is understood by representatives of different cultures, grasping the meaning, is actively developed. In such circumstances, the study of understanding as a phenomenon of intercultural communication is very relevant.

The syncretic character of the content side of the sign from a semiotic point of view is the presence of several determinants, which predetermine both the ontology of the language as a whole and its specific manifestation at the semantic level.

In this study, the task is to consider the phenomenon of understanding in the modern convergence of cultures. The space of meanings and knowledge arising in the development of culture is very extensive, there is a tendency to polysemantic unity. All social and individual human life takes place in the language environment. Language and speech, as its practical embodiment, is the space in which a person is, the environment in which he lives. Language reflects the universal conditions of human life, which allow him to constantly navigate and act meaningfully in the ever-changing world of interpersonal communication. The quality of intercultural communication, as well as communication within one culture, depends on the quality of understanding achieved.

\section{METHODOLOGY}

The empirical basis of the study was the results of the analysis-traditional and formalized (content analysis) journalistic speeches for 1995-2015:

a) in all-Russian Newspapers ("Izvestia", "Komsomolskaya Pravda", "Arguments and Facts", "General newspaper", "Literary newspaper", "Pravda");

b) in regional Newspapers ("New Kuban", "Mordovia-7 days", "Eurasia-Ufa", " Evening Saransk»);

c) in the information programs of the Central and local television and radio broadcasting (15689 media texts) from the point of view of their compliance (noncompliance) with the requirements of communicative qualities of public speech, as well as the normative use of speech means. 
Materials for the study were extracted by continuous sampling from these Newspapers. These texts are also available on the Internet, in addition to the printed versions. These Newspapers reflect the dynamics of the current situation at the Federal and regional levels of Russia for 20 years. This approach makes it possible to track changes that are total and / or regional in nature. The time interval of 20 years is because it makes it possible to assess the quality of transformations in the mental base of a person due to globalization and migration processes. The total sample of texts is 76,385 journalistic works and media reports. We believe that a smaller sample does not make it possible to trace the stability of transformations in the language picture of the world.

Theoretical and methodological basis of our work are activity-based and hermeneutic approaches presented in works of foreign and domestic authors on the problems of understanding in linguistics, philosophy of language, communication theory, cultural studies, etc. the paper deals with the linguocultural analysis of the problem of understanding in intercultural communication, studies the relationship between language and culture in the aspect of understanding, considered the ideological aspect of the problem understanding and the correlation of national images of the world.

The hypothesis of the study. We assume that the existing systems of concepts (categories) in the consciousness of a person, and, consequently, the essential features of his thinking are determined by the specific language, the carrier of which this person is; therefore, the mental representations of speakers of different languages may not coincide. The achievement of understanding in intercultural communication is possible by combining the original and newly mastered mental image at the level of deep language meta-structures.

The object of this study is intercultural communication; the subject is understanding as a result of intercultural communication process.

The research material is represented by texts of different functional and style affiliation, reflecting structural and functional variants of language use, correlated with spheres of human social activity. The empirical material is presented not by a static set of sources, that is, by a limited set of texts of a certain functional affiliation, but by a dynamic system covering the entire volume of the introspective knowledge of the researcher about the object being analyzed.

As a fundamental principle of the research, a dialectical approach was used to study the problem of the relationship between language and thinking, processes of human cognition, and the sign representation of fragments of human experience and knowledge.

The specificity of the material under study, the purpose and objectives of the study determined the use of deductive and inductive methods, as well as such general scientific methods and techniques as analysis and synthesis, classification and generalization.

\section{ANALYSIS}

The synergistic development of the text, carried out in the mind of the individual perceiving the text, is carried out based on the core of the text as a structural-semantic prototype representing the most stable part. The marginal zone determines the variable projection of the text. Consequently, the higher the proportion of denotative attribution of content to the designated object and the uniformity of the communicative orientation of the text, the greater the likelihood of core stability. Accordingly, the more voluminous the share of the subjective, individualpersonal in the reference projection of the text, the higher the number of interpretation options for this projection, representing conceptually marked correlates of the source text.

The cognitive stratification of a macro-label predetermines the explication of a discourse topic in the form of a macroposition or macro-structure corresponding to a dynamic communication model.

Globalization creates mass consumption enclaves that provoke intracultural conflicts. In response, ethnocultures mobilize defensive cultural strategies of the traditionalist and fundamentalist plan, as a spontaneous value-semantic reflection on cultural aggression (Al-Fadhat, F., \& Raihan Nadhir, M. 2019). These strategies can be destructive for themselves, screening out the positive elements of globalization.

The enclaves of a mass consumer society are pockets of intercultural and intracultural conflicts. Globalization affects the status of ethnocultures in the system of ethnocultural communications. The main spheres of ethnocultural interaction are distinguished: 1) Cultural and civilizational interaction (complimentary, consensus and conflict); 2) state cultural policy; 3) the expansion of mass western culture; 4) reactions to globalization. Thus, ethnocultural communication is a complex interference of the four main processes of ethnocultural interaction. The radical changes taking place both in the world and in Russian society lately have actualized the theme of ethnic being. The "ethnic revolution", "ethnic expansion" in all spheres of social life, an even greater desire of peoples to preserve their language, culture, identity, traditions and customs have become adequate "answers" to the processes of globalization. The continuous growth of ethnic conflicts and wars led many scientists to radically reconsider the old paradigms, to abandon the old "inheritance", the theories of "natural extinction of ethnicity" [7].

The semantic aspect of semiosis, established in the triad of the relation: syntactics, semantics, pragmatics, is explicable in the most obvious terms in terms of language content to consciousness ("sense" / "meaning" / "concept") and to reality ("referent" / "denotat" / "thing"). Contaminating with the semantic side of the sign, the syntactic sets the relation of the sign to other signs in the system (paradigmatic level) and in the text (syntactic).

Semiotic models of the communicative sign, based on the invariant triad of the sides of semiosis, are determined by the existing theoretical models of communication.

In contrast to the code model, the intentional transmission function, which expresses the emotive and axiological components of semiosis, prevails in the communication communication model.

New meanings appear in places of intense dialogue, namely: the border zone, migration regions, and the virtual dialogue zone on the Internet [8]. In addition, the study of the adaptation of foreign languages by the modern language personality under the influence of the electronic-digital format of society deserves special attention.

As a result of these multidirectional processes, the language itself undergoes tremendous changes. Hence the emergence of not only new words, but also semantic fields. For example: rus. "frendy" (friends), rus. "frendessy" (friends), rus. "zafrenditsa" (to be friends), rus "rasfrenditsa" (stop being friends) from an English friend 
became more common due to the expansion of social networks; "mutualno" (mutually), "mutualniy" (mutual, common) from English, French mutual in the same meaning.

In our opinion, under the influence of the penetration of foreign languages (primarily English) into the sphere of everyday communication, there is a gradual change in the identity of the linguistic personality towards transculture.

The core of linguoculturology and intercultural communication is "textual" human activity, which, serving other profiles of these Sciences, is increasingly crystallized into an independent form with "internal" goals of communicative-cognitive and socio-psychological properties. And in this synergetic field, culture can be considered as a sign system, as a Text (with a capital letter), acting as a source of meaning, that is, having both a communicative and symbolic nature. In any information and communication disposition, mass media culture deals with the practical world in the era of globalization, where each object is evaluated in connection with its usefulness (uselessness), that is, with the positive (negative) activity of a person transforming reality, including its speech modes. This leads to the conditionality of the content-formal nature of mass communication, on the one hand, the socio-cultural situation, and on the other-its ability (within certain limits) to cause a change in this situation.

This process is a response adaptation response of a traditional language personality to the massive invasion of a foreign language culture. New semantic spaces arise:

"Roflit" in Russian - Ruffle (1. Laugh, laugh, have fun; 2. Troll, make fun, humiliate, speak sarcastically, keeping a serious face) comes from the abbreviation: in rus. ROFL rolling on floor laughing - rus. "roflyanochka" (violent laughter) - "rofel" - (funny joke, nickel rofel, funny rofel). Lack of sustainable entities, fast updating of information, obsolescence of knowledge, now provocative discourses on ethno-racial, religious, gender themes and other features of the new reality are pushing the individual to search for new and new social identities.

Under the influence of migration processes, the host community is looking for its own ways in new language realities. Thus, to refer to migrants from Central Asian countries and regions of the youth Russian environment, the lexeme "abrek" is used to designate also migrants from countries of the former Soviet Union [9].

It cannot be said that with the intensification of globalization, only derivatives from the English language are used. Passion for Asian cultures also brought its own specifics. For example, the word "makne" came from the Korean language, thanks to Korean pop culture. There is a competition of two makne. Our makne is the best! This lexeme means the youngest in the group, derived from 막내 ("manne") in the sense of the youngest.

Pendulum, educational, tourist migration to European countries led to the penetration and entry of such new realities as the mascot (lucky talisman depicting a person, animal, bird or fantastic creature) used as part of a brand book from fr., it. Mascotte in the same meaning: Bloody Cheburashka - our mascot; Mardi Gras (designation of the holiday, a holiday with a carnival, figurative, originally carnival festivals in New Orleans) from Fr. Mardi Gras Fat Tuesday (carnival celebration with the absence of a single concept): Will you go to Mardi Gras? Well, you made a cool Mardi Gras!

Today it has become a vital necessity for a young person to possess the knowledge and ability to find his place in this diverse reality. We believe that the electronic digital format of globalization processes in the linguistic and migratory context first causes passive migration at the linguomental level, only later turning into active migration with a transition to another linguistic culture as a language for encoding and decoding information.

From the position of the phenomenological approach, the generation of the text is due to the interpreter's strategy of the addresser, that, that specific way of perceiving reality, constitutes the cognitive basis of the individual reference of fragments and situations.

Individual and social components in the structure of personality are expressed in the epistemic complex, that is, the totality of knowledge, attitudes, stereotypes, reflecting the statics and dynamics of social and individual conventions. The unit of this complex is a concept, modeled in cognitive studies as a construct, objectified at the mental level and verbalized in language signs [10]. The anthropic nature of the concept implementation mode and its dependence on the space of individual and idioethnic mentality are noted. From the position of the cognitive approach, the structural-semantic organization of a macronoun is secondary to the conceptual sphere of an individual, a semiotic formation, mediated by the dynamics of the processes of interiorization and interaction. Defining the conceptual level as a text-forming variable of the text, firstly, the hierarchical nature of the organization of an individual's conceptual system is established, secondly, the semiology of the text is mediated by the macro concept, thirdly, the variability of interpretation of the text content is mediated by the allegomorphism of conceptual systems.

As a model reflecting the information hierarchy of a macro, a "planar" theory is presented, based on the principle of disjunction of cognitive levels defined by the triad of discursive functions; reference, creative and communicative [11].

In the plane projection of the information levels of the macro, the levels of explicit, conventional information having a linguistic expression, and implicit information based on a system of decoded discursive implications are distinguished [12].

From the position of the hermeneutic theory of meaning, the treatment of any knowledge as interpretation is formulated [11].

The typology of linguistic signs on the parameter of discreteness is carried out on the basis of the "principle of double division", which establishes the degree of division of complex signs into component segments as a sequence of components. This typological principle is an integral part of the modeling of a semiotic system, since it allows one to structure paradigmically and syntagmatically organized stratification of its units.

The property of linguistic signs not only to fix that and translate the conceptualized value is explicated in the theory of double reference of units: in the system and in speech.

To the current information situation in Russia, where the desire of actors of speech communication to move from a state of "chaos" to a state of "order" is still weakly visible, the concept of "communicative strategy" is quite applied. It is a self-organizing complex of value-oriented means semantic, linguistic, stylistic-for optimal implementation of communicative intentions, taking into account the interests of everyone. This complex must necessarily be incorporated into the program-target methodology and methodology of the state information policy in the transitional society of the era of globalization and migration. This type of policy, in turn, comes to a qualitative level of social management (in relation to information processes). 
Thus, we tried to substantiate the linguoculturological concept of mass information process in the transitional society of globalization as a set of ontological, axiological, epistemological, sociolinguistic provisions and conclusions that systematically prove and functionally interpret the pragmatic (culture-forming) role of social intercultural communication, focused on the use of different cultural and linguistic codes.

The phenomenon of understanding has long interested scientists working in different branches of knowledge. Psychologists, philologists, teachers worked on this problem. Gradually, an independent science of understanding, called hermeneutics, developed in the paradigm of philosophical Sciences. Research in this area has expanded with the expansion of what is understood. The basic concepts of the science of understanding - cognition, rationality, reflection, interpretation-were highlighted Matthew James Alexander Little [13].

Communication is traditionally called the exchange of values (information) between individuals through a common system of symbols (signs), language signs. American scientist J. Bird [14] identified more 40 different approaches to communication in different areas, including architecture, anthropology, psychology, politics and many others. However, he shows more interest in the subject of neurophysiological reactions of understanding in intercultural communication. We will not enter into a discussion with the author but let us note that not all statements are equivalent in different languages.

In the mechanistic paradigm, communication is understood as a unidirectional process of encoding and transmitting information from the source and receiving information by the recipient of the message. In the activity approach, communication is understood as a joint activity of communication participants (communicants), during which a common view of things and actions with them are developed. For example, these are the views of Swedish scientists on Primate communication [15].

As we can see, communication does not occur only in human social systems. A certain kind of communication is typical for animals (mating dances of birds, the mating of capercaillie, language of bees, vocalizations of primates, etc.), and for mechanisms, i.e. objects created by man (pipelines, Sewerage, transport, Telegraph and telephone signals, the relationship of computers on the Internet, etc.).

The mechanistic approach considers a person as a mechanism whose actions can be described by certain finite rules, the context of the external environment of communication is considered as noise, interference. This approach is typical for machine learning professionals who train artificial intelligence NLP. For example, questionanswer and dialogue systems (chatbots) such as Amazon Alexa, Alice are already classic and recognizable examples of dialogue systems. However, experts have solved many NLP problems for the productive operation of these systems. So, text classification helps to determine whether we fall into one of the scenarios goal-oriented chatbot. For example, "the question of exchange rates." Relationship extraction is needed to determine the placeholders of the script template, and the task of conducting a dialogue on common topics ("chatter") will help us in a situation where we are not in any of the scenarios [16].

The other approach is characterized by procedural, continuality, contextuality. In General, the latter approach is closer to the reality of life and more humanistic. At the same time, for some applications of communication theory, one can use mechanistic metaphors (exchange of information), without forgetting the conventions of the term.

The discipline of communication theory was first claimed in the USA. Communication theory is based on the idea of communication between the Creator and the recipient of speech through verbal text. This initial position can be examined both linguistically and rhetorically.

The word communication comes from lat. Communico -I make common, I connect, I communicate. Communication in human society means communication, exchange of thoughts, knowledge, feelings, patterns of behavior, etc. It is more correct (in the internal form of the term) to say that we want to share our thoughts, share our feelings with someone. This is a very significant observation that divides the approach to communication into two paradigms: mechanistic and activity.

The concept of linguistic significance, which unites several theories focused on the description of the factors determining the semantics of a sign, represents the current approaches to solving the problem of the gnoseology of a language. The reflective nature of the sign, objectified in meaning, connects the two poles of materialization: material reality and the continuum of language units. In the linguosemiotic interpretation of the essence of the sign, objective reality and the human consciousness reflecting it are established as determinants [17].

From the very beginning, intercultural communication had a pronounced applied orientation. This is not only a science, but also a set of skills that can and should be owned [18]. First, these skills are necessary for those whose professional activity is connected with the interaction between cultures, when mistakes and communicative failures lead to other failures - in training, in negotiations, to inefficient work of the team, to social tension. Achieving adequate understanding in intercultural communication is an extremely important task. Thus, the Russian researcherArabist N. V. Dubinina [19] observed for more than 20 years the linguistic and cultural changes that occurred in the language consciousness of students studying Arabic in depth. She tried to create and test such a dynamic model that would reflect the process of realizing the potential of the language system and the specifics of the transformation of the secondary language personality of the Arab student, its capabilities in the period of mastering Arabic as a foreign language, immersion in the academic Arabic discourse. An undoubted advantage is the distinction between arabistics and academic Arabic-language discourse made by the author for the first time, the dissertation introduced new definitions: academic Arabic-language discourse, theological Arabic-language discourse. This distinction makes the choice of the object and the cognitivepragmatic aspect of analysis is scientifically valid and relevant to intercultural communication that focused on scientific research anthropological approach to explore real linguistic identity, to study the implicit structure with the aim of establishing communicative individuality of students-Arabists [19].

The study revealed that the migration of the Arab population in Asia the EU is the result of the combined tractor and push factors from the countries of entry and exit of migrants. One of the main pushing factors is the high demographic burden, low level of economic development, political and religious persecution, civil wars in the countries of the region. The attractive factors of migration to the EU are the high level of economic development and quality of life, their favorable migration policy, providing for the provision of social benefits to refugees [20]. 
This work is interesting because it touches on issues of cultural susceptibility of modern young people. We see this work as relevant in the context of the ISIS blockchain of fake news [21]. It is no coincidence that the Central concepts in the field of applied intercultural communication are intercultural competence and intercultural sensitivity. Increasing intercultural sensitivity in the face of the multiplying differences, uncertainty, ambiguity and changes that characterize modern society, becomes an important component of the professional suitability of the specialist. Adequate understanding in cross-cultural communication is a major factor in enhancing intercultural sensitivity and the formation of intercultural competence.

The problem of understanding in intercultural communication is a poorly developed topic. The specificity of understanding in intercultural communication is associated with the need for an interdisciplinary approach that considers the complexity of the phenomenon of understanding as such, and the variety of factors that complicate intercultural communication.

Attempts to comprehend the phenomenon of understanding in intercultural communication relate to the theory of "local cultures" developed by Yu.M. Lotman in the framework of social philosophy.

"Local culture" as a complete integral symbolic system of cultural meanings reflects the completeness of human being and humanity in the products of his creativity. The isolation and self-sufficiency of local culture is manifested in its opposition (sometimes quite rigid) to other cultures. The " upper "part of one local culture can be quite close to the "upper" part of another. But at the level of "grassroots" culture, in terms of individual household opposition, the gap is large. This is expressed in the relevant Proverbs and sayings, stereotypes of perception of representatives of another culture can be realized only through the knowledge of another culture, otherwise it is incomplete, since there is no subject of comparison. Communication between cultures is also localized, and a common communication space arises within these cultures. In this case, the area of intersection (identity) is relatively small, and the area of the disjoint is huge.

The domain of identity is a prerequisite for the penetration into the domain of the non-natural, unknown to the penetrating culture, and therefore non-trivial and interesting. The value of dialogue turns out to be related not to the intersecting part, but to the transfer of information between the non-intersecting parts. This puts us face to face with an insoluble contradiction: we are interested in communicating with the situation that makes communication difficult, and in the limit makes it impossible [22].

The philosophically mediated substantiation of the process of semiosis predetermines the idea of parallelism of language and objective reality, formulated in line with logical positivism. Consistent with the ideas of logical positivism, the unilateral model of the linguistic sign removes the question of the semantic nature of meaning, thereby leveling the content side of the language. We also see the transformation of verbal-paraverbal behavior under the influence of intercultural communication in social media and in cinema [23].

Phenomenologically oriented studies, dating back to the philosophical postulates of Plato, Aristotle, the theory of the popular spirit of V. von Humboldt, the phenomenology of E. Husserl, A. Losev, M. Heidegger, presented an anthropocentric understanding of semiotic processes. Objects of extralinguistic reality are considered as given, the hidden essence of which is revealed by human consciousness and becomes the result of interiorization as a mental operation, creating in parallel to the fragments of the world a system of their cognitive analogs. In the existing philosophically grounded theories of meaning, several positions have been outlined in understanding the nature of meaning, which are embodied in the corresponding models and descriptions. The ostensional definition of the meaning of a sign explicates the objective determinant of its content within the framework of positivistically oriented logical semantics. Functional interpretation of the value comes from the characteristics of the object for its use.

The relational understanding of meaning actualizes the logical-psychological processuality in the formation of the content of a sign objectified as a relative given and formed by the relationship of name and meaning [24, 25]. The scientific search is carried out taking into account the productive ideas of researchers belonging to various areas of philology, such as, in particular, pragmatics [26-30], semiotics (R. Barth, Y.M. Lotman, U.Eco, and others) [22, 31, 32], literary studies (M.M. Bakhtin, V.V. Vinogradov, etc.) [33-36].

The transcultural competence of the linguistic personality as a kind of "navigation system" allows the individual, being in the subcultural space, to overcome the subjectivity of assessing "his own" and "other", seeing their differences, to hold each of them and take an individual position in the dialogue of cultures [7, 37]. It is the knowledge of the area of discrepancy (initial misunderstanding) of cultures that enriches them with new meanings and new values, although it complicates the fact of communication, and, ultimately, makes culture unknowable for another in the absolute sense. Therefore, here we can only talk about a conditional coincidence, a kind of dynamic identity of different cultures. As native speakers (bearers of meaning) are specific people who are formed in a specific historical cultural situation and carry the features of this formation, the traditions of their ethnic group, what can be called historical memory. Therefore, the absolute identity of representatives of different cultures is impossible.

The adaptation potential of passive linguistic migration implies the adoption of a different linguistic culture in active use in the native language space.

"Dialogue of cultures" is the cognition of another culture through one's own, and one's own through another through cultural interpretation and adaptation of cultures to each other in terms of semantic discrepancy and even conflict. But conflict is one of the forms of contradiction that allows the system (in this case, the space of two cultures) to develop. The result of this development is mutual understanding between cultures (and their individual representatives). Therefore, language is not just a means of communication or information transfer, but an important mechanism of cultural communication [4]. The dialogue of cultures is a heterogeneous superimposition of meanings on each other, and a kind of pulsating symbiosis of meanings, getting used to each other, sometimes directly passing one into another at the linguistic level.

The dynamic processes of the internationalization of higher education have revealed an insufficient level of development of key social competencies among students. The results of our research allow us to conclude that a transcultural personality in a real dialogue of cultures demonstrates the use of mechanisms for transformation and decoding of attitudes and attitudes. 
Thus, the knowledge of culture is a cardinal condition for the humane resolution of the accumulated problems of globalization.

\section{CONCLUSION}

Interpretation of a sign from the standpoint of anthropocentrism expresses as a semiotic constant the property of intentionality, which consists in the fact that a material exhibitor acquires the status of a sign if it actualizes in the mind of the sender and the recipient some information that is derived not only from the natural (causal, spatial, temporal, etc.) connections between entities of the real world, and being the result of the internalized mastering of segments of reality and intended to expansion and cumulation by means of an existing semiotic code.

I. The concept of understanding as a phenomenon of intercultural communication, based on the characteristic of understanding from the point of view of linguoculturalism as a cultural phenomenon (the result of adequate perception of other cultural representations) and linguistic in nature (the result of adequate perception of collocation restrictions governing the use of language) and including:

1) national-specific pictures of the world of communicants; 2) the degree of verbalization of the deep content of the message, characteristic of different languages; 3) phonetic and lexical-semantic structure of interacting languages; 4) cultural scenarios used by communicants and their role in the context of interacting cultures; 5) the rationale leading levels of communicative competence, relevant content and semantic field communication, according to the number laid down in the communication of meaning and understanding. So, the logic of theory development in the Humanities largely follows the logic of social phenomena development. We see this in the case of migration theory and globalization. The complexity of the structure of migration flows, the development of temporary types of migration, the expansion of international population migration, its "interweaving" in the globalizing system of the world, the formation of stable migration flows between certain countries-all these phenomena have set the researchers the task of explaining them. Migration and globalization of the population is a multidimensional phenomenon, the causes and consequences of which should be considered at the macro and micro levels. These processes take place in the context of other social, economic, demographic, and political processes that find expression in language. The decision to migrate is always made at the micro level - at the level of the individual and the family. Similarly, the consequences of migration and globalization not only affect the immediate participants in the movement process, but also affect all the structures in which they existed before and after the act of migration, including changes in the semantic internal picture of the world, and in a certain sense, the established microcosms of the verbal picture of the world of the individual. Today, migrations are massive, and these interactions are particularly noticeable. They can change - already under the influence of globalization and migration processes - and stimulate new waves of change in the conceptual system of the world of participants in these processes. Theoretical understanding of this complex system of relationships is possible only on the basis of the system approach, which is presented in this article, but requires further development.

\section{LIMITATION AND STUDY FORWARD}

Characteristics of cultural and linguistic factors that have a destructive impact on the process and results of understanding in intercultural communication: 1) mismatch of national and cultural pictures of the world of communicants; 2) inability to verbalize. In deep conceptual structures there is a large content at the level of the subconscious, which is not objectified in the language, because it does not lend itself to verbalization; 3) linguistic factors that impede communication can be classified by levels of perception: phonetic, semantic, syntactic and textual; 4) psychological barrier; 5) ethnocentric attitudes of foreign cultural communicants; 6) the desire of communicants to preserve their own cultural identity; 7) inadequate use of paralinguistic means.

We assume that the conditions of optimization of understanding in intercultural communication should be studied more deeply, in such directions as: 1) adequate command of the language of communication and the desire of communicants to achieve maximum linguistic-cultural and conceptual equivalence of lexical units of interacting languages; 2) modification of the world picture by a foreign cultural communicant by combining the original and newly mastered image of reality within his mentality; 3 ) awareness by communicants of the objectively existing impossibility of complete verbalization of mental structures; 5) linking codes and concepts between interacting cultures in the process of communication, etc.

\section{ACKNOWLEDGMENT}

This paper was financially supported by Ministry of Education and Science of Russian Federation on the program to improve the competitiveness of Peoples' Friendship University of Russia (PFUR University, RUDN-university) among the worlds leading research and education centers in the 2016-2020.

\section{REFERENCES}

[1] Ph. Fargues, Arab Migration to Europe: Trends and Policies, International Migration Review 38(4) (2006) 1348-1371. DOI: 10.1111/j.1747-7379.2004.tb00240.x

[2] E.N. Luchinskaya, I.S. Karabulatova, V.I. Tkhorik, V.V. Zelenskaya, S.A. Golubtsov, New aspects of intercultural communication discourse modeling in the context of globalization and migration, Opción 34(85) (2018) 789-800.

[3] A. Toffler, Futuroshok, Lan', 1997.

[4] I.S. Karabulatova, K.V. Vorontsov, Digital linguistical migrationology: the possibilities of artificial intelligence in the study of migration processes, in: II World Congress in real and virtual mode "West-East: crossing cultures", 2-6 October 2019, Japan, Kyoto Sange University, Scientific and practical materials of the 2nd world Congress in Japan, 2019, Kyoto, Kyoto Sange, vol. 2, pp. 760-766. 
[5] Yu.S. Stepanov, V mire semiotiki. Semiotika: Antologiya, Delovayakniga, 2001.

[6] E. Benvenist, Obshchayalingvistika, BGK im. I.A.Boduena de Kurtene, 1998.

[7] Y.N. Ebzeeva, I.S. Karabulatova, D.A. Nakisbaev, The Problems of Transformation of the Personal Identity in a Modern Migrant, Astra Salvensis 11(1) (2018) 729738 .

[8] I.S. Karabulatova, Z.V. Polivara, Turkic and Slavs: bi-polylinguism in globalization and migrations (on an example of Tumen region), Middle East Journal of Scientific Research 17(6) (2013) 832-836.

[9] I. Karabulatova, E. Ermakova, The concept "abrek" in the modern russian linguistic consciousness: from the mountaineer-robber to the terrorist-migrant, Man in India 97(23) (2017) 439-445.

[10] Z.R. Khachmafova, I.S. Karabulatova, S.V. Serebryakova, A.V. Zinkovskaya, E.N. Ermakova, The Specifics of an Estimate discourse of gender stereotypes in small forms of Folklore in a Network Discourse of Electronic and Information society at the Beginning of 21 ct Century, Pertanika Journal of Social Science \& Humanities 25(S) (2017) 137-150.

[11] G. Rakisheva, I. Karabulatova, A. Abibulaeva, Ethno-sociocultural deviations in the educational environment of the Modern Eurasian Higher Education Institution as a reflection of transcultural globalization factors, Man in India 97(23) (2017) 115-131.

[12] V.V. Barabash, A.S. Bobryshova, O.I. Lepilkina, I.S. Karabulatova, The specific of the interpretation of tragedy over Sinay (October 31, 2015) as a focus of information attention of the "VKONTAKTE" Social Network, Astra Salvensis 11(1) (2018) 289-310.

[13] M.J.A. Little, Understanding the phenomenon of trafficking commodities, University of Canterbury, 2018.

[14] J.J. Bird, Practical approaches to Communication, in: Interactivity Foundation, Parkersburg, 2009.

[15] K. Liebal, L. Oña, Different Approaches to Meaning in Primate Gestural and Vocal Communication, Front. Psychol. 9 (2018) 478. DOI: https://doi.org/10.3389/fpsyg.2018.00478

[16] K.A. Naidenova, O.A. Nevzorova, Machine learning in natural language processing problems: a review of the current state of research, Scientific notes of Kazan University. Series Physical and mathematical Sciences 4 (2008) 5-24.

[17] I. Karabulatova, Kh. Vildanov, A. Zinchenko, E. Vasilishina, A. Vassilenko, Problems of transformation matrices modern multicultural identity of the person in the variability of the discourse of identity Electronic Information Society, Pertanika Journal of Social Science \& Humanities 25(S) (2017) 1-16.
[18] D.R. Sabirova, R.R. Khanipova, Innovative approaches to teaching and learning english as second and English as foreign language in multilingual education, Humanities \& Social Sciences Reviews 7(6) (2019) 45-48. DOI:

https://doi.org/10.18510/hssr.2019.7610

[19] N.V. Dubinina, Transformation of the secondary language personality of an Arab student in the academic Arabic discourse: abstract of the thesis of the candidate of philological Sciences, Maikop, Adyghe state University, 2018, 28 p.

[20] M.M. Agafoshin, Factors of migration of the population of Arab countries of Asia to the EU, in: Proceeding of higher educational institutions, Volga region. Natural Sciences, 2017, vol. 2(18).

[21] I.S. Karabulatova, The specifics of individual behavior under the influence of the work of a recruiter of extremist orientation in an electronic digital society, in: Advances in Social Science, Education and Humanities Research. International Conference on Man-Power-LawGovernance: Interdisciplinary Approaches, Atlantic Press, 2019, vol. 374. DOI:

https://doi.org/10.2991/mplg-ia-19.2019.28

[22] Yu.M. Lotman, Inside the thinking worlds: man text - semiosphere - history, Tart. University, Yaz. rus cultures, 1996.

[23] R. Izmaylov, A. Blagoveshchenskaya, N.

Kuvshinov, I. Sokolova, Cinematography as an element of the ideological system of kemalism, Humanities \& Social Sciences Reviews 7(5) (2019) 650-653. DOI: https://doi.org/10.18510/hssr.2019.7575

[24] V.F. Petrenko, Osnovy psikhosemantiki, Publishing house of Moscow University, 1997.

[25] I.S. Karabulatova, The problems of linguistic modeling of new Eurasian linguistic personality in multilinguistic and mental environment (by example of onomasphere), Middle East Journal of Scientific Research 17(6) (2013) 791-795.

[26] N.D. Arutyunova, The speech act. Linguistic Encyclopedic Dictionary, 1990.

[27] N.D. Arutyunova, The addressee's factor, News of the Academy of Sciences of the USSR. A series of literature and language 40(4) (1981).

[28] T. Bulygina, On the boundaries and content of pragmatics, News of the Academy of Sciences of the USSR. A series of literature and language 40(4) (1981).

[29] H.P. Grice, Logic and Conversation. Syntax and Semantics: Speech Acts, 1975.

[30] M. Krongauz, Semantics: 2nd ed., Academy, 2005.

[31] R. Bart, Selected Works: Semiotics. Poetics, Progress, 1994. 
[32] W. Eco, The role of the reader. Studies on the semiotics of the text, Symposium; RSUH, 2005.

[33] M. Bakhtin, The problem of text in linguistics, philology and other humanities: the experience of philosophical analysis. Russian literature: from theory of literature to the structure of text: an anthology, Institute of the peoples of Russia, 1997.

[34] M. Bakhtin, Aesthetics of verbal creativity. 2nd ed., Art, 1986.

[35] V. Vinogradov, On the theory of artistic speech, Higher. wk., 1971.

[36] V.V. Vinogradov, On the language of artistic prose, Science, 1980.

[37] Yu. Ebzeeva, I. Mitrofanova, N. Avsineeva, The image of a migrant in modern Russian TV Journalism discourse, Man in India 97 (2017) 525-532. 